\title{
Antimicrobial resistance in Neisseria gonorrhoeae isolates and gonorrhoea treatment in the Republic of Belarus, Eastern Europe, 2009-2019
}

Aliaksandra Aniskevich¹, Iryna Shimanskaya', Iryna Boiko ${ }^{2,3}$, Tatyana Golubovskaya ${ }^{4}$, Daniel Golparian³, Iryna Stanislavova ${ }^{4}$, Susanne Jacobsson ${ }^{3}$, Aliaksandr Adaskevich ${ }^{4}$ and Magnus Unemo ${ }^{3^{*}}$ (i)

\begin{abstract}
Background: Limited antimicrobial resistance (AMR) data for Neisseria gonorrhoeae are available in Eastern Europe. We investigated AMR in N. gonorrhoeae isolates in the Republic of Belarus from 2009 to 2019, antimicrobial treatment recommended nationally, and treatment given to patients with gonorrhoea.

Methods: N. gonorrhoeae isolates $(n=522)$ cultured in three regions of Belarus in 2009-2019 were examined. Determination of minimum inhibitory concentrations (MICS) of eight antimicrobials was performed using Etest. Resistance breakpoints from the European Committee on Antimicrobial Susceptibility Testing were applied where available. A Nitrocefin test identified $\beta$-lactamase production. Gonorrhoea treatment for 1652 patients was also analysed. Statistical significance was determined by the Z-test, Fisher's exact test, or Mann-Whitney $U$ test with $p$ values of $<0.05$ indicating significance.

Results: In total, $27.8 \%$ of the N. gonorrhoeae isolates were resistant to tetracycline, $24.7 \%$ to ciprofloxacin, $7.0 \%$ to benzylpenicillin, $2.7 \%$ to cefixime, and $0.8 \%$ to azithromycin. No isolates were resistant to ceftriaxone, spectinomycin, or gentamicin. However, 14 (2.7\%) isolates had a ceftriaxone MIC of $0.125 \mathrm{mg} / \mathrm{L}$, exactly at the resistance breakpoint (MIC > $0.125 \mathrm{mg} / \mathrm{L}$ ). Only one $(0.2 \%)$ isolate, from 2013, produced $\beta$-lactamase. From 2009 to 2019, the levels of resistance to ciprofloxacin and tetracycline were relatively high and stable. Resistance to cefixime was not identified before 2013 but peaked at 22.2\% in 2017. Only sporadic isolates with resistance to azithromycin were found in $2009(n=1), 2012(n=1)$, and 2018-2019 $(n=2)$. Overall, $862(52.2 \%)$ patients received first-line treatment according to national guidelines (ceftriaxone $1 \mathrm{~g}$ ). However, 154 (9.3\%) patients received a nationally recommended alternative treatment (cefixime $400 \mathrm{mg}$ or ofloxacin $400 \mathrm{mg}$ ), and 636 (38.5\%) were given nonrecommended treatment.
\end{abstract}

\footnotetext{
* Correspondence: magnus_unemo@yahoo.com

${ }^{3}$ World Health Organization Collaborating Centre for Gonorrhoea and Other Sexually Transmitted Infections (STIs), National Reference Laboratory for STIs, Department of Laboratory Medicine, Clinical Microbiology, Faculty of Medicine and Health, Örebro University, Örebro, Sweden

Full list of author information is available at the end of the article
}

(c) The Author(s). 2021 Open Access This article is licensed under a Creative Commons Attribution 4.0 International License, which permits use, sharing, adaptation, distribution and reproduction in any medium or format, as long as you give appropriate credit to the original author(s) and the source, provide a link to the Creative Commons licence, and indicate if changes were made. The images or other third party material in this article are included in the article's Creative Commons licence, unless indicated otherwise in a credit line to the material. If material is not included in the article's Creative Commons licence and your intended use is not permitted by statutory regulation or exceeds the permitted use, you will need to obtain permission directly from the copyright holder. To view a copy of this licence, visit http://creativecommons.org/licenses/by/4.0/ The Creative Commons Public Domain Dedication waiver (http://creativecommons.org/publicdomain/zero/1.0/) applies to the data made available in this article, unless otherwise stated in a credit line to the data. 
Conclusions: The gonococcal resistance to ciprofloxacin and tetracycline was high, however, the resistance to azithromycin was low and no resistance to ceftriaxone was identified. Ceftriaxone $1 \mathrm{~g}$ can continuously be recommended as empiric first-line gonorrhoea therapy in Belarus. Fluoroquinolones should not be prescribed for treatment if susceptibility has not been confirmed by testing. Timely updating and high compliance with national evidence-based gonorrhoea treatment guidelines based on quality-assured AMR data are imperative. The need for continued, improved and enhanced surveillance of gonococcal AMR in Belarus is evident.

Keywords: Neisseria gonorrhoeae, Antimicrobial resistance, Surveillance, Treatment, Ceftriaxone, Azithromycin, Belarus, Eastern Europe

\section{Background}

Gonorrhoea, etiological agent: Neisseria gonorrhoeae, is one of the most common sexually transmitted infections (STIs) worldwide [1-3]. According to the World Health Organization (WHO), in 201686.9 million new adult cases of gonorrhoea were estimated [2]. In the Republic of Belarus the incidence of reported gonorrhoea (cases per 100,000 inhabitants) has substantially decreased, i.e., from 63 in 2005 to 44.4 in 2009, and finally, to 10.5 in 2018 [4]. The incidence of gonorrhoea in Belarus and many other East European countries is most likely underestimated because of limited testing (especially pharyngeal and rectal samples), insufficient use of nucleic acid amplification tests, incomplete reporting using multiple methods and epidemiological surveillance [5-7].

Alarmingly, the level of antimicrobial resistance (AMR) in Neisseria gonorrhoeae to a wide range of drugs has increased dramatically worldwide over the past decades, including first-line treatment [3, 5, 8-11]. Ceftriaxone, an extended-spectrum cephalosporin (ESC), is the last option for first-line empiric monotherapy internationally. It is a concern that in vitro and clinically decreased susceptibility or resistance to ceftriaxone has been reported from many countries [3, 5, 8-28]. This has resulted in that the WHO global gonorrhoea treatment guidelines and international and national guidelines in Europe, Australia, and Canada recommend antimicrobial combination therapies, mostly ceftriaxone $250-1000 \mathrm{mg} \times 1$ intramuscularly (IM) combined with azithromycin $1-2 \mathrm{~g} \times 1$ orally $[8,11,29,30]$. However, some countries, such as Japan, Ukraine and, since 2019 and 2020, the United Kingdom and USA, respectively, recommend high-dose ( $1 \mathrm{~g}$ except in the USA where 500 $\mathrm{mg}$ is recommended) ceftriaxone monotherapy, i.e., when chlamydial infection has been excluded [31-34]. Nevertheless, the first treatment failure with a recommended dual therapy for gonorrhoea was reported in 2016 [27]. In 2018, the first gonococcal strain with ceftriaxone resistance combined with high-level resistance to azithromycin was identified in England [25] and Australia [35].

WHO has developed a global action plan to control the spread and minimise the impact of AMR in $N$. gonorrhoeae [10]. One of its key strategies is to globally enhance quality-assured gonococcal AMR surveillance; to identify emerging AMR, monitor AMR trends, and ensure effective patient management by timely and evidence-based refinements of treatment guidelines. In the European Union/European Economic Area (EU/ EEA) the European Gonococcal Antimicrobial Surveillance Programme (Euro-GASP) has been monitoring the patterns of AMR since 2004 [12, 36-38]. It is a grave concern that gonococcal AMR surveillance is dreadfully limited $[5,6]$ in the non-EU/EEA countries of the WHO European Region, and only available in Ukraine, Belarus, and Russia [33, 39-44].

The empirical treatment of gonococcal infections in Belarus is guided by the Clinical protocol for the diagnosis and treatment of patients with STIs and approved by the order of the Ministry of Health of the Republic of Belarus 10/29/2009, No. 1020 (below referred to as '2009 Belarusian national gonorrhoea guideline') [45]. For treatment of uncomplicated gonorrhoea, recommended first-line therapy is ceftriaxone $1 \mathrm{~g} \times 1 \mathrm{IM}$. Recommended alternative regimens are cefixime $400 \mathrm{mg} \times 1$ orally or spectinomycin $2 \mathrm{~g} \times 1 \mathrm{IM}$ for men and $4 \mathrm{~g} \times 1$ IM for women or ofloxacin $400 \mathrm{mg} \times 1$ orally, or lomefloxacin $800 \mathrm{mg} \times 1$ orally [45]. To treat complicated gonorrhoea ceftriaxone $1 \mathrm{~g}$ IM or IV every $24 \mathrm{~h}$ for 7 days is the recommended first-line therapy. Recommended alternative regimens are spectinomycin $2 \mathrm{~g}$ IM every $12 \mathrm{~h}$ for 7 days or ofloxacin $200 \mathrm{mg}$ orally every 12 h for 7-14 days, or lomefloxacin $400 \mathrm{mg}$ orally every 24 $\mathrm{h}$ for 7-14 days [45]. Notable, spectinomycin is currently not available throughout Belarus [46].

The aims of this study were to 1) analyse the trends in N. gonorrhoeae AMR levels in Belarus (2009-2019), 2) review the antimicrobial treatments recommended nationally as well as compliance with these recommendations in Belarus, and 3) provide quality-assured gonococcal AMR data for informing the 2009 Belarusian national gonorrhoea guideline [45].

\section{Methods}

\section{Study population}

Gonorrhoea patients $(n=522)$ diagnosed in accordance with standard care at the following STI Healthcare Institutions were included in the study: Mogilev Regional 
Dermatovenerologic Dispensary, Mogilev $(n=409)$, Minsk City Clinical Dermatovenerologic Dispensary, Minsk $(n=83)$, and Vitebsk Regional Dermatovenerologic Dispensary, Vitebsk $(n=30)$ in Belarus, September 2009-June 2015 and July 2017-December 2019. For a description of longitudinal AMR data, this cohort includes previously published data (273 patients) from $2009(n=80)$ [39] and 2010-2013 $(n=193)$ [40]. Cervical and urethral specimens from females and males, respectively, were collected in accordance with standard care and delivered to the bacteriological laboratory in Amies Transport Medium with Charcoal (Research and production center Chemmedsynthsis, Minsk, Belarus). Sex and age of the patients were recorded but no patient identification data. Exclusion criterium was: not confirmed gonococcal infection. All patients and their sexual partners were to be treated in accordance with the 2009 Belarusian national gonorrhoea guideline [45].

\section{Culture of Neisseria gonorrhoeae}

All urogenital swabs were inoculated on the Chocolate $\operatorname{agar}^{\mathrm{m} \mathrm{m}}+$ PolyViteX VCAT3 plates (bioMerieux, Marcyl'Etoile, France), which were subsequently incubated in $5 \pm$ $1 \% \mathrm{CO}_{2}$-enriched humid atmosphere at $36 \pm 1{ }^{\circ} \mathrm{C}$ for $24 \mathrm{~h}$ and, if negative, for an additional $24 \mathrm{~h}$. Suspected gonococcal colonies were verified as $N$. gonorrhoeae based on identification of microscopy (Gram-negative diplococci), oxidase reaction, a Vitek $^{\circ} 2$ automatic bacteriological analyser (bioMerieux, Durham, NC, USA) with Vitek $^{\circ} 2 \mathrm{NH}$ ID cards (bioMerieux, Marcy-l'Etoile, France), a polymerase chain reaction assay (AmpliSens Neisseria gonorrhoeae-screen-Fl; InterLabServices, Moscow, Russia), and matrix-assisted laser desorption-ionisation time-of-flight mass spectrometry (MALDI-TOF MS; Microflex LT, Bruker Daltonik, Bremen, Germany), according to the manufacturer's instructions.

The isolates were stored in accordance with standard care in a liquid preservation medium containing trypticase-soy broth, yeast extract, agar, and horse serum in liquid nitrogen $\left(-196^{\circ} \mathrm{C}\right)$ or a low-temperature freezer $\left(-80^{\circ} \mathrm{C}\right)$.

\section{Antimicrobial susceptibility testing}

At the WHO Collaborating Centre for Gonorrhoea and other STIs, Sweden, the minimum inhibitory concentrations (MICs; $\mathrm{mg} / \mathrm{L}$ ) of ceftriaxone, cefixime, azithromycin, spectinomycin, ciprofloxacin, tetracycline, benzylpenicillin, and gentamicin were determined by Etest (bioMerieux, Marcy-l'Etoile, France), following the manufacturer's instructions and as described previously $[33,39,40]$. Whole MIC dilutions were used for interpretation and clinical susceptibility (S) and resistance (R) breakpoints stated by the European Committee on Antimicrobial Susceptibility Testing (EUCAST) [47] were applied, where available. For azithromycin, no clinical breakpoints exist, and the
EUCAST azithromycin epidemiological cut-off value (ECOFF) of MIC $>1 \mathrm{mg} / \mathrm{L}$ [47] was applied to indicate isolates with azithromycin resistance determinants (considered as azithromycin resistant below). For gentamicin, breakpoints from a previous publication were used [48]. The Nitrocefin test (Oxoid, Basingstoke, England) was used to identify $\beta$-lactamase producing gonococcal strains. For quality controls of the antimicrobial susceptibility testing, the 2016 WHO N. gonorrhoeae reference strains [49] were used.

\section{Treatment of gonorrhoea}

The treatment of patients with gonorrhoea $(n=1652)$ diagnosed in accordance with standard care at the Minsk City Clinical Dermatovenerologic Dispensary in 2013$2018(n=749)$ and Mogilev Regional Dermatovenerologic Dispensary in 2010-2019 $(n=903)$ were analysed. Uncomplicated and complicated gonorrhoea cases were defined according to the international statistical classification of diseases and related health problems [50]. Gonorrhoea treatment compliance with the 2009 Belarusian national gonorrhoea guideline [45] was evaluated.

\section{Statistical analysis}

Statistical analysis was performed using MedCalc Statistical Software v18.11.3 (MedCalc Software bvba, Ostend, Belgium). The $95 \%$ confidence interval (95\% CI) was calculated using the exact binomial distribution. The Ztest, Fisher's exact test, and Mann-Whitney $U$ test were used to compare groups, as appropriate. The level of significance was set at $\mathrm{P}<0.05$.

\section{Results}

Patients and Neisseria gonorrhoeae isolates

$N$. gonorrhoeae isolates (one per patient) from urogenital sites of 522 patients were examined: 430 (82.4\%) males, 84 (16.1\%) females and eight (1.5\%) with sex not reported. The isolates were cultured in Mogilev (78.4\%, 409/522), the capital city Minsk (15.9\%, 83/522), and Vitebsk (5.7\%, 30/522) in $2009(n=81), 2010(n=72), 2011(n=6), 2012$ ( $n=75), 2013$ ( $n=101), 2014(n=56), 2015$ ( $n=17), 2017$ $(n=36)$, in $2018(n=19)$, and $2019(n=59)$.

Demographic data (sex and age) were available from $514 / 522$ (98.5\%) patients. Briefly, the median age for men was 25 years (range 16-61 years) and for women, also 25 years (range 16-74 years). The sex and age distributions were similar in 2009-2019. The median malefemale ratio was 5.9 (range 1.8-7.6), with decreasing trends over time.

\section{Antimicrobial susceptibility of Neisseria gonorrhoeae isolates $(n=522)$ from Belarus, 2009-2019}

The overall antimicrobial susceptibility of all $N$. gonorrhoeae isolates $(n=522)$ is summarised in Table 1. 
Briefly, in 2018-2019 the resistance to tetracycline, ciprofloxacin, cefixime, benzylpenicillin, and azithromycin was 26.9, 16.7, 5.1, 3.8, and 2.6\%, respectively. During 2009-2019, the resistance levels were as follows: tetracycline $27.8 \%$ (range: $17.8-34.7 \%$ ), ciprofloxacin $24.7 \%$ (9.6-34.6\%), benzylpenicillin $7.0 \%(2.8-11.1 \%)$, cefixime $2.7 \%(0-22.2 \%)$, and azithromycin $0.8 \%(0-2.6 \%)$ (Table $1)$. Only one $(0.2 \%) \beta$-lactamase-producing isolate was found (in 2013). No isolates resistant to ceftriaxone, spectinomycin, or gentamicin were detected (Table 1). However, $14(2.7 \%)$ isolates had a ceftriaxone MIC of $0.125 \mathrm{mg} / \mathrm{L}$, precisely on the resistance breakpoint of MIC $>0.125 \mathrm{mg} / \mathrm{L}$. Additionally, $31.6 \%$ of the isolates had a decreased susceptibility to gentamicin.

During 2009-2019, the level of resistance to tetracycline was relatively high and stable. The level of resistance to ciprofloxacin significantly decreased to $9.6 \%$ in $2014-$ 2015 , but significantly increased to $30.6 \%$ in 2017 ( $P<$ $0.05)$. The level of resistance to benzylpenicillin nonsignificantly fluctuated, i.e., from 2.8 to $11.1 \%$ over the years. Of note, no resistance to cefixime was found before 2013 (when 2.0\% resistance was identified); however, the cefixime resistance then significantly increased to a peak of $22.2 \%$ in $2017(P<0.05)$. Only sporadic isolates with resistance to azithromycin were found in 2009 $(n=1,1.2 \%), 2012(n=1,1.3 \%)$, and 2018-2019 $(n=2$, 2.6\%) (Table 1).

The MIC distributions for ceftriaxone and azithromycin, included in the internationally recommended firstline dual antimicrobial therapy $[8,11,29]$, and cefixime are presented in Fig. 1.

In total, $2.7 \%(14 / 522)$ of the isolates had a ceftriaxone MIC of $0.125 \mathrm{mg} / \mathrm{L}$, which is on the ceftriaxone resistance breakpoint [47]. The proportion of isolates with a ceftriaxone MIC of $\leq 0.016 \mathrm{mg} / \mathrm{L}$ was $85.2 \%$, and in general, the annual MIC distribution for ceftriaxone appeared to shift to lower MICs during 2009-2019 (data not shown). For cefixime, 78.7\% (411/522) of the isolates had a MIC of $\leq 0.016 \mathrm{mg} / \mathrm{L}$; however, $2.7 \%(14 / 522)$ of the isolates were resistant to cefixime, highest $\mathrm{MIC}=2$ $\mathrm{mg} / \mathrm{L}$ (one isolate in 2013), and additionally, 1.7\% (9/ 522 ) of the isolates had a cefixime MIC of $0.125 \mathrm{mg} / \mathrm{L}$, i.e., exactly on the cefixime resistance breakpoint [47]. Except for four (0.8\%) azithromycin-resistant isolates (MICs $2-12 \mathrm{mg} / \mathrm{L}$ ), the azithromycin MIC distribution appeared to represent a wild-type distribution.

\section{Antimicrobial treatment of gonorrhoea patients in Belarus, 2010-2019}

Compliance with the treatment of gonococcal infections to the 2009 Belarusian national gonorrhoea guideline [45] at the Minsk City Clinical Dermatovenerologic Dispensary (2013-2018) and the Mogilev Regional Clinical Dermatovenerologic Dispensary (2010-2019) for 1652 patients is described in Table 2.

Many antimicrobial treatment regimens were administered (Table 2). Overall, only 862 (52.2\%) patients received the recommended first-line treatment (ceftriaxone $1 \mathrm{~g}$ (uncomplicated gonorrhoea) or $>1 \mathrm{~g}$ (complicated gonorrhoea) as monotherapy or in combination with other antimicrobials) in accordance with the 2009 Belarusian national gonorrhoea guideline [45]. Some 154 (9.3\%) patients were given a recommended alternative treatment (cefixime $400 \mathrm{mg}$ or ofloxacin $400 \mathrm{mg}$ as a single oral dose) [45]. Consequently, $38.5 \%$ of the patients received treatment not compliant with the 2009 Belarusian national gonorrhoea guideline [45]. Worryingly, notwithstanding the high level of ciprofloxacin resistance, ofloxacin 400 $\mathrm{mg} \times 1$ was given to $149(9.0 \%)$ patients.

Table 1 Antimicrobial susceptibility in Neisseria gonorrhoeae isolates ( $n=522)$ from Minsk, Mogilev, and Vitebsk, Belarus, $2009-2019$

\begin{tabular}{|c|c|c|c|c|c|c|c|c|}
\hline \multirow[t]{3}{*}{ Antimicrobials } & \multicolumn{7}{|c|}{ Susceptible (S)/Susceptible, increased exposure (I)/Resistant (R), \% ${ }^{a}$} & \multirow{3}{*}{$\begin{array}{l}\text { Total }^{b} \\
n=522\end{array}$} \\
\hline & $2009^{b}$ & $2010-2011^{b}$ & $2012^{b}$ & $2013^{b}$ & 2014-2015 & 2017 & $2018-2019$ & \\
\hline & $n=81$ & $n=78$ & $n=75$ & $n=101$ & $n=73$ & $n=36$ & $n=78$ & \\
\hline $\mathrm{CRO}$ & $100 / \mathrm{NA} / 0$ & 100/NA/0 & 100/NA/0 & 100/NA/0 & 100/NA/0 & 100/NA/0 & 100/NA/0 & 100/NA/0 \\
\hline CFM & 100/NA/0 & 100/NA/0 & 100/NA/0 & 98.0/NA/2.0 & 100/NA/0 & 77.8/NA/22.2 & 94.9/NA/5.1 & 97.3/NA/2.7 \\
\hline AZM & 98.8/NA/1.2 & 100/NA/0 & 98.7/NA/1.3 & 100/NA/0 & 100/NA/0 & 100/NA/0 & $97.4 / \mathrm{NA} / 2.6$ & 99.2/NA/0.8 \\
\hline SPC & 100/NA/0 & 100/NA/0 & 100/NA/0 & 100/NA/0 & 100/NA/0 & 100/NA/0 & 100/NA/0 & 100/NA/0 \\
\hline CIP & $65.4 / 0 / 34.6$ & $64.1 / 2.6 / 33.3$ & $78.7 / 0 / 21.3$ & $72.3 / 0 / 27.7$ & $90.4 / 0 / 9.6$ & $69.4 / 0 / 30.6$ & $83.3 / 0 / 16.7$ & $74.9 / 0.4 / 24.7$ \\
\hline PEN & 29.6/60.5/9.9 & $-1-1-$ & $62.6 / 30.7 / 6.7$ & $59.4 / 31.7 / 8.9$ & $80.8 / 16.4 / 2.8$ & $55.6 / 33.3 / 11.1$ & $51.3 / 44.9 / 3.8$ & $56.3 / 36.7 / 7.0$ \\
\hline TET & $55.5 / 21 / 23.5$ & $56.4 / 10.3 / 33.3$ & $56 / 9.3 / 34.7$ & 62.4/8.9/28.7 & $76.7 / 5.5 / 17.8$ & $69.4 / 0 / 30.6$ & $61.5 / 11.5 / 26.9$ & $61.9 / 10.3 / 27.8$ \\
\hline GEN & $72.8 / 27.2 / 0$ & $97.4 / 2.6 / 0$ & $58.7 / 41.3 / 0$ & $40.6 / 59.4 / 0$ & $67.1 / 32.9 / 0$ & $55.6 / 44.4 / 0$ & $87.2 / 12.8 / 0$ & $68.4 / 31.6 / 0$ \\
\hline
\end{tabular}

CRO Ceftriaxone, CFM Cefixime, AZM Azithromycin, SPC Spectinomycin, CIP Ciprofloxacin, PEN Benzylpenicillin, TET Tetracycline, GEN Gentamicin, NA Not applicable, - , not tested

${ }^{a}$ The clinical breakpoints (susceptible, resistant) were as follows: ceftriaxone and cefixime (MIC $\leq 0.125 \mathrm{mg} / \mathrm{L}, \mathrm{MIC}>0.125 \mathrm{mg} / \mathrm{L}$ ), ciprofloxacin (MIC $\leq 0.032 \mathrm{mg} / \mathrm{L}$, $\mathrm{MIC}>0.064 \mathrm{mg} / \mathrm{L})$, azithromycin (MIC $\leq 1 \mathrm{mg} / \mathrm{L}, \mathrm{MIC}>1 \mathrm{mg} / \mathrm{L})$, spectinomycin (MIC $\leq 64 \mathrm{mg} / \mathrm{L}, \mathrm{MIC}>64 \mathrm{mg} / \mathrm{L})$, benzylpenicillin $(\mathrm{MIC} \leq 0.064 \mathrm{mg} / \mathrm{L}, \mathrm{MIC}>1.0 \mathrm{mg} / \mathrm{L})$, tetracycline (MIC $\leq 0.5 \mathrm{mg} / \mathrm{L}, \mathrm{MIC}>1.0 \mathrm{mg} / \mathrm{L})$, and gentamicin $(\mathrm{MIC} \leq 4 \mathrm{mg} / \mathrm{L}, \mathrm{MIC}>16 \mathrm{mg} / \mathrm{L})[47,48]$.

${ }^{\mathrm{b}}$ Of the 335 isolates from 2009-2013, 273 have been previously published [39, 40] 


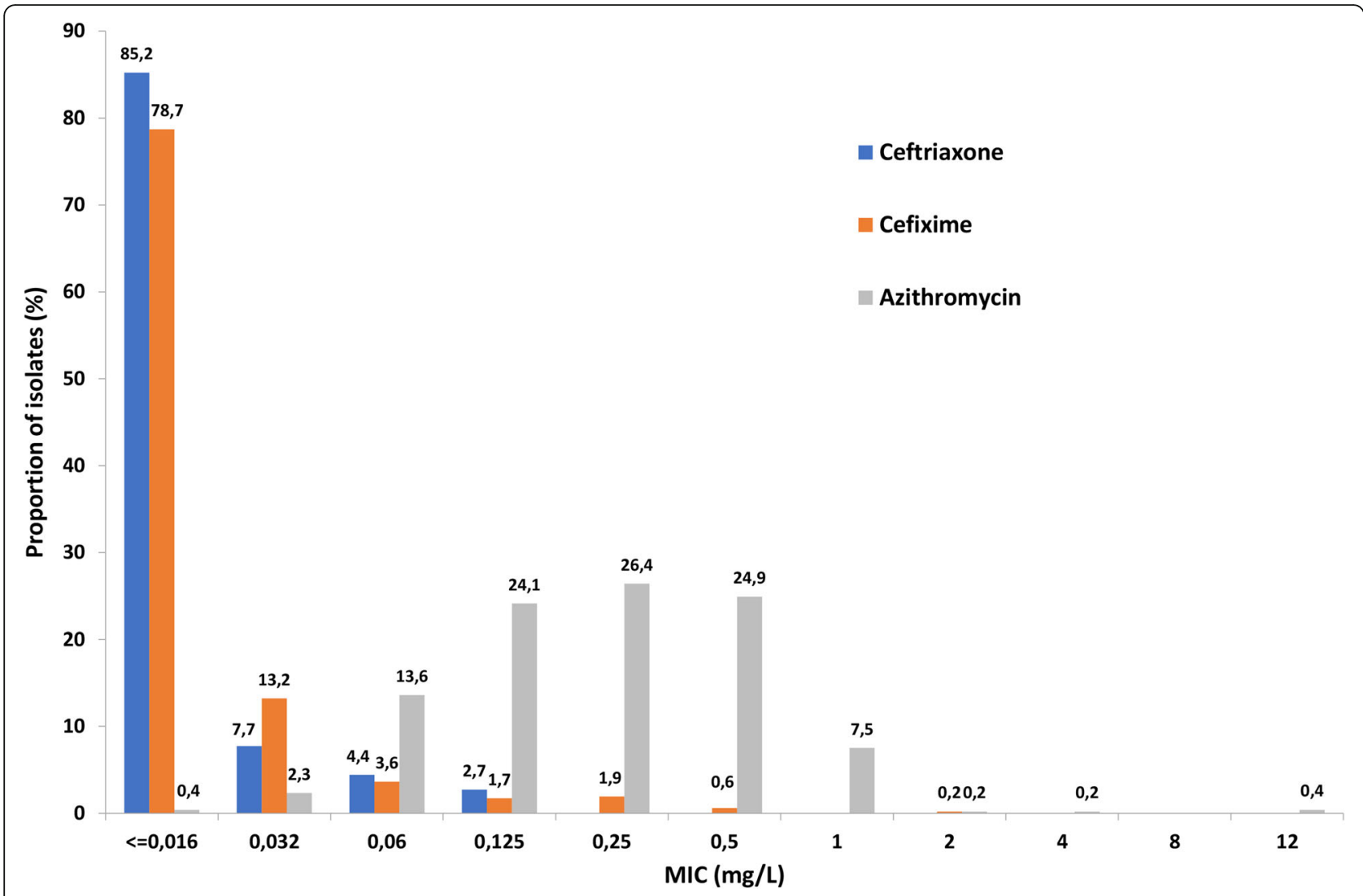

Fig. 1 MIC distributions for ceftriaxone, cefixime, and azithromycin for Neisseria gonorrhoeae isolates $(n=522)$ from Belarus, 2009-2019

Table 2 Compliance with the 2009 Belarusian national gonorrhoea guideline [45] in Minsk (749 patients, 2013-2018) and Mogilev (903 patients, 2010-2019), Belarus

\begin{tabular}{|c|c|c|}
\hline Prescribed antimicrobials & $\begin{array}{l}\text { Minsk } \\
\text { No. }(\%, 95 \mathrm{Cl})\end{array}$ & $\begin{array}{l}\text { Mogilev } \\
\text { No. }(\%, 95 \mathrm{Cl})\end{array}$ \\
\hline \multicolumn{3}{|l|}{ Recommended first-line treatment $[45]$} \\
\hline $\begin{array}{l}\text { CRO } 1 \mathrm{~g} \times 1 \mathrm{IM} \text { (uncomplicated gonorrhoea) or CRO } 1 \mathrm{~g} \times 1 \mathrm{IM} \text { or IV every } 24 \mathrm{~h}, 7 \text { days (complicated } \\
\text { gonorrhoea) })^{\mathrm{a}}\end{array}$ & $\begin{array}{l}354(47.3,43.7- \\
51.0)\end{array}$ & $\begin{array}{l}508(56.3,53.0- \\
59.6)\end{array}$ \\
\hline \multicolumn{3}{|l|}{ Alternative treatment $[45]$} \\
\hline CFM $400 \mathrm{mg} \times 1$ orally & $5(0.7,0.2-1.6)$ & 0 \\
\hline OFX $400 \mathrm{mg} \times 1$ orally & $26(3.5,2.3-5.1)$ & $\begin{array}{l}123(13.6,11.4- \\
16.0)\end{array}$ \\
\hline \multicolumn{3}{|l|}{ Non-compliant treatment } \\
\hline Non-compliant antimicrobials or doses given, generally higher than recommended & $\begin{array}{l}364(48.6,45.0- \\
52.3)^{b}\end{array}$ & $\begin{array}{l}272(30.1,27.1- \\
33.2)^{c}\end{array}$ \\
\hline
\end{tabular}

No. Number, Cl Confidence interval, CRO Ceftriaxone, IM Intramuscularly, IV Intravenously, CFM Cefixime, OFX Ofloxacin

${ }^{a}$ Frequently, additional antimicrobials were given to treat other non-viral STIs, which had been confirmed or not excluded by appropriate laboratory diagnostics. These included doxycycline, other tetracyclines, different macrolides, fluoroquinolones, oral cephalosporins, penicillins, and nitroimidazoles

${ }^{\mathrm{b}}$ More than $1 \mathrm{~g}$ of ceftriaxone was quite often given; approximately $10 \%$ of the patients received benzylpenicillin, about $5 \%$ a tetracycline/macrolide regimen, and one $(0.1 \%)$ patient was given rifampicin

${ }^{\mathrm{C}}$ More than $1 \mathrm{~g}$ of ceftriaxone was somewhat frequently given. A benzylpenicillin regimen was rarely given, and for a few patients, $>400 \mathrm{mg}$ ofloxacin or a tetracycline/macrolide regimen was administered 


\section{Discussion}

We report the first $N$. gonorrhoeae AMR surveillance data, quality-assured according to WHO standards [5, $49,51,52]$, for isolates cultured in Belarus during an extended period (from 2009 to 2019 in Minsk, Vitebsk, and Mogilev). AMR levels were significant and comparable to those in neighbouring Russia [41-44], EU/EEA countries $[12,36,37]$, and many other countries internationally $[5,52]$. However, the AMR levels were clearly higher than in neighbouring Ukraine [33].

In Belarus, the resistance levels to the earlier recommended gonorrhoea therapeutic antimicrobials tetracycline, ciprofloxacin, and benzylpenicillin were relatively high, i.e., at $27.8,24.7$, and $7 \%$, respectively. These antimicrobials should not be recommended or used for empirical gonorrhoea treatment in Belarus, which is in concordance with most other countries $[3,5,8-12,28-$ $34,36,37,39-44]$. It is a grave concern that fluoroquinolones (ofloxacin and lomefloxacin) remain to be recommended in the 2009 Belarusian national gonorrhoea guideline [45], i.e., despite the high resistance to ciprofloxacin. Furthermore, particularly ofloxacin was also frequently used in gonorrhoea monotherapy or in combination with other antimicrobials. When susceptibility has not been confirmed by laboratory testing, fluoroquinolones should not be used for treatment [8]. Accordingly, ofloxacin and lomefloxacin should be excluded from the empiric treatment recommended in the Belarusian national gonorrhoea guideline [45]. Of note, gonococcal strains producing $\beta$-lactamase were very rare $(0.2 \%, 1 / 522$ isolates) in Belarus, as earlier observed also in the neighbouring East European countries Russia and Ukraine [33, 39-44]. Accordingly, few $\beta$-lactamase producing strains appear to have emerged in Belarus or, if imported, managed to spread in the country. However, $7 \%$ of the 522 isolates had a chromosomally-mediated resistance to benzylpenicillin, and additionally, 36.7\% displayed a decreased susceptibility. Azithromycin resistance $(0.8 \%)$ was rare compared to most EU/EEA countries [12, 36, 37] and only sporadic isolates $(n=4)$ resistant to azithromycin were found. The overall resistance to cefixime was $2.7 \%$, fluctuating from 0 to $22.2 \%$ in 2017. Only 36 gonococcal isolates, however, were examined in 2017 and the high cefixime resistance this year was suspected to mainly be caused by a single gonococcal clone. No gonococcal resistance to ceftriaxone, spectinomycin, and gentamicin was identified. However, spectinomycin is currently not available throughout Belarus [46]. The lack of ceftriaxone resistance and, in general, relatively low ceftriaxone MICs may be because of the long tradition to use ceftriaxone in high dose $(1 \mathrm{~g}$ in monotherapy or dual antimicrobial therapy) for treatment of gonorrhoea [45] and that the less potent oral ESC cefixime has been rarely used for treatment of gonorrhoea in Belarus. Alarmingly, the compliance with the 2009 Belarusian national gonorrhoea guideline [45] was relatively low and many noncompliant suboptimal antimicrobials were prescribed to a large proportion of patients. This lack of compliance may select AMR in $N$. gonorrhoeae, etiological agents of other STIs, and bystander organisms [3, 53]. Moreover, in Belarus antimicrobials, such as several penicillins and tetracyclines, are readily available over-the-counter in pharmacies without prescription, which is crucial to abandon to decrease the high level of self-medication and a further selection of AMR.

Our study has some limitations. First, gonococcal isolates were collected in only three of the six regions of Belarus. However, considering that these three regions represent $60 \%$ of the Belarusian population, including the capital city Minsk (https://en.wikipedia.org/wiki/ Regions_of_Belarus), this geographical bias should be limited and the results should be generalisable to the wider population. Second, the number of isolates per year was low. Third, no data were collected on pharyngeal or rectal specimens. Finally, no data on epidemiological or clinical characteristics (e.g., sexual behaviour and treatment outcomes) were available. Consequently, the gonococcal AMR surveillance in Belarus should be further improved and enhanced by increasing the number of isolates and representativeness of isolates collected each year, ideally including additional regions and collection of extragenital specimens such as pharyngeal and rectal specimens. Finally, gonococcal AMR surveillance in Belarus should also include more detailed patient epidemiological and clinical data.

\section{Conclusions}

The present study reports the first gonococcal AMR surveillance data for isolates cultured in Belarus over an extended period (i.e., from 2009 to 2019) in the Minsk, Mogilev, and Vitebsk regions, quality-assured according to WHO standards $[5,49,51,52]$. Based on the gonococcal AMR data presented in this paper, Belarus has also participated in the WHO Global GASP [5]. Briefly, in 2009-2019 the gonococcal population circulating in Belarus showed stable and high resistance to tetracycline, ciprofloxacin, and benzylpenicillin. More sporadic resistance to azithromycin and fluctuating resistance to cefixime were also found. However, no resistance to ceftriaxone, spectinomycin, or gentamicin was identified. Consequently, ceftriaxone $1 \mathrm{~g}$ can continuously be recommended as empiric first-line gonorrhoea therapy in Belarus. When susceptibility has not been confirmed by laboratory testing, fluoroquinolones should not be used for gonorrhoea treatment. Continued, improved and enhanced N. gonorrhoeae AMR surveillance of gonococcal AMR in Belarus is imperative to timely inform revisions 
of the national gonorrhoea guideline [45] in Belarus. Finally, a comparison of the Belarusian gonococcal population with the $N$. gonorrhoeae strains spreading internationally, i.e., using whole-genome sequencing, which is used in the Euro-GASP surveillance [37, 54] and has also been recently applied in gonococcal AMR surveillance in Ukraine [55] and many other countries across the world [56-62], would be valuable.

\section{Abbreviations}

AMR: Antimicrobial resistance; ECOFF: Epidemiological cut-off value; ESC: Extended-spectrum cephalosporin; EU/EEA: European Union/European Economic Area; EUCAST: European Committee on Antimicrobial Susceptibility Testing; Euro-GASP: European Gonococcal Antimicrobial Surveillance Programme; IM: Intramuscularly; IV: Intravenously; MIC: Minimum inhibitory concentration; WHO: World Health Organization; 2009 Belarusian national gonorrhoea guideline: Clinical protocol for the diagnosis and treatment of patients with sexually transmitted infections approved by order of the Ministry of Health of the Republic of Belarus 10/29/2009, No. 1020.

\section{Acknowledgements}

We are very grateful to all the staff at the Mogilev Regional Skin and Venereal Diseases Dispensary and the Minsk City Clinical Dermatovenerologic Dispensary, and to Dr. Leslie Shaps for proofreading and editing the revised manuscript.

\section{Authors' contributions}

AA1, IS1, and MU designed the study. TG, DG, IS2, SJ, AA1 and AA2 participated in collecting samples or laboratory examinations. AA1, with the support of IS1, IB, and MU, analysed all the data and wrote the first draft of the manuscript. All authors were involved in finalising the manuscript and approved the final version of the manuscript.

\section{Funding}

The study was supported by the Örebro County Council Research Committee and the Foundation for Medical Research at Örebro University Hospital, Örebro, Sweden. The funding bodies had no role in the design of the study and collection, analysis, and interpretation of data and in writing the manuscript. Open Access funding provided by Örebro University.

\section{Availability of data and materials}

The datasets used or analysed during the current study are available from the corresponding author on reasonable request.

\section{Declarations}

\section{Ethics approval and consent to participate}

In the present study, all examined gonococcal isolates were cultured and preserved as part of the routine diagnostics (standard care) from 2009 to 2019, and no patient identification data were available when data were retrospectively analysed. No patients were recruited only for the present study, and all patients were managed (diagnosed and treated) in accordance with standard care outside the present study from 2009 to 2019. Accordingly, no consent from the patients diagnosed and treated in routine practice (standard care) from 2009 to 2019 or any separate ethical approval for the present study was deemed necessary or required. Nevertheless, despite this an approval of the study protocol and publication of its results was obtained by the Expert Commission at the Belarusian Medical Academy of Postgraduate Education (BelMAPO), Minsk, Belarus (Date of final decision: July 6, 2020).

\section{Consent for publication}

Not applicable.

\section{Competing interests}

The authors declare that they have no competing interests.

\section{Author details}

Belarusian Medical Academy of Postgraduate Education, Minsk, Belarus. ${ }^{2}$ Department of Functional and Laboratory Diagnostics, I. Horbachevsky Ternopil National Medical University, Ternopil, Ukraine. ${ }^{3}$ World Health Organization Collaborating Centre for Gonorrhoea and Other Sexually Transmitted Infections (STIS), National Reference Laboratory for STIS, Department of Laboratory Medicine, Clinical Microbiology, Faculty of Medicine and Health, Örebro University, Örebro, Sweden. ${ }^{4}$ Mogilev Regional Skin and Venereal Diseases Dispensary, Mogilev, Belarus.

Received: 18 August 2020 Accepted: 14 May 2021

Published online: 02 June 2021

\section{References}

1. Kirkcaldy RD, Weston E, Segurado AC, Hughes G. Epidemiology of gonorrhoea: a global perspective. Sex Health. 2019;16(5):401-11. https://doi. org/10.1071/SH19061.

2. Rowley J, Vander Hoorn S, Korenromp E, Low N, Unemo M, Abu-Raddad LJ, et al. Chlamydia, gonorrhoea, trichomoniasis and syphilis: global prevalence and incidence estimates, 2016. Bull World Health Organ. 2019;97(8):548-62P. https://doi.org/10.2471/BLT.18.228486

3. Unemo M, Seifert HS, Hook EW III, Hawkes S, Ndowa F, Dillon JR. Gonorrhoea. Nat Rev Dis Primers. 2019;5(1):79. https://doi.org/10.1038/s41 572-019-0128-6.

4. Ministry of Health of the Republic of Belarus State Institution «Republican Scientific and Practical Center for Medical Technologies, Information, Administration and Management of Health». Public health in the Republic of Belarus: An official statistics collection, 2018. Minsk: RNMB, vol. 261; 2019. (in Russian) http://minzdrav.gov.by/upload/dadvfiles/letter/ Здравоохранение.pdf (Accessed 19 July 2020)

5. Unemo M, Lahra MM, Cole M, Galarza P, Ndowa F, Martin I, et al. World Health Organization global gonococcal antimicrobial surveillance program (WHO GASP): review of new data and evidence to inform international collaborative actions and research efforts. Sex Health. 2019;16(5):412-25. https://doi.org/10.1071/SH19023.

6. Unemo M, Ison CA, Cole M, Spiteri G, van de Laar M, Khotenashvili L. Gonorrhoea and gonococcal antimicrobial resistance surveillance networks in the WHO European Region, including the independent countries of the former Soviet Union. Sex Transm Infect. 2013;89(Suppl 4):v42-iv6. https:// doi.org/10.1136/sextrans-2012-050909.

7. Boiko I, Golparian D, Krynytska I, Unemo M. High prevalence of Chlamydia trachomatis, Neisseria gonorrhoeae and particularly Trichomonas vaginalis diagnosed using US FDA-approved Aptima molecular tests and evaluation of conventional routine diagnostic tests in Ternopil, Ukraine. APMIS. 2019; 127(9):627-34. https://doi.org/10.1111/apm.12975.

8. Unemo M, Ross JDC, Serwin AB, Gomberg M, Cusini M, Jensen JS. European guideline for the diagnosis and treatment of gonorrhoea in adults. Int J STD AIDS. 2020;2020:956462420949126. https://doi.org/10.1177/095646242094 9126 Epub ahead of print.

9. Unemo M, Shafer WM. Antimicrobial resistance in Neisseria gonorrhoeae in the 21st century: past, evolution, and future. Clin Microbiol Rev. 2014;27(3): 587-613. https://doi.org/10.1128/CMR.00010-14.

10. World Health Organization (WHO). Global action plan to control the spread and impact of antimicrobial resistance in Neisseria gonorrhoeae. Geneva: WHO; 2012. https://apps.who.int/iris/handle/10665/44863 (Accessed 19 July 2020).

11. World Health Organization (WHO). WHO guidelines for the treatment of Neisseria gonorrhoeae. Geneva: WHO; 2016. http://www.who.int/ reproductivehealth/publications/rtis/gonorrhoea-treatment-guidelines/en/ (Accessed 19 July 2020)

12. Day MJ, Spiteri G, Jacobsson S, Woodford N, Amato-Gauci AJ, Cole MJ, et al. Stably high azithromycin resistance and decreasing ceftriaxone susceptibility in Neisseria gonorrhoeae in 25 European countries, 2016. BMC Infect Dis. 2018;18(1):609. https://doi.org/10.1186/s12879-018-3528-4.

13. Ohnishi M, Golparian D, Shimuta K, Saika T, Hoshina S, Iwasaku K, et al. Is Neisseria gonorrhoeae initiating a future era of untreatable gonorrhea? Detailed characterisation of the first strain with high-level resistance to ceftriaxone. Antimicrob Agents Chemother. 2011;55(7):3538-45. https://doi. org/10.1128/AAC.00325-11

14. Cámara J, Serra J, Ayats J, Bastida T, Carnicer-Pont D, Andreu A, et al. Molecular characterisation of two high-level ceftriaxone-resistant Neisseria 
gonorrhoeae isolates detected in Catalonia, Spain. J Antimicrob Chemother. 2012;67(8):1858-60. https://doi.org/10.1093/jac/dks162.

15. Unemo M, Golparian D, Nicholas R, Ohnishi M, Gallay A, Sednaoui P. Highlevel cefixime- and ceftriaxone-resistant $N$. gonorrhoeae in France: novel penA mosaic allele in a successful international clone causes treatment failure. Antimicrob Agents Chemother. 2012;56(3):1273-80. https://doi.org/1 0.1128/AAC.05760-11.

16. Gianecini R, Oviedo C, Stafforini G, Galarza P. Neisseria gonorrhoeae resistant to ceftriaxone and cefixime, Argentina. Emerg Infect Dis. 2016;22(6):1139-41. https://doi.org/10.3201/eid2206.152091.

17. Lahra MM, Ryder N, While DM. A new multidrug-resistant strain of Neisseria gonorrhoeae in Australia. N Engl J Med. 2014;371(19):1850-1. https://doi. org/10.1056/NEJMc1408109.

18. Deguchi T, Yasuda M, Hatazaki K, Kameyama K, Horie K, Kato T, et al. New clinical strain of Neisseria gonorrhoeae with decreased susceptibility to ceftriaxone, Japan. Emerg Infect Dis. 2016;22(1):142-4. https://doi.org/10.32 01/eid2201.150868.

19. Nakayama S-I, Shimuta K, Furubayashi K-I, Kawahata T, Unemo M, Ohnishi M. New ceftriaxone and multidrug-resistant Neisseria gonorrhoeae strain with a novel mosaic penA gene isolated in Japan. Antimicrob Agents Chemother. 2016;60(7):4339-41. https://doi.org/10.1128/AAC.00504-16.

20. Lahra MM, Martin I, Demczuk W, Jennison AV, Lee Kl, Nakayama SI, et al. Cooperative recognition of internationally disseminated ceftriaxone-resistant Neisseria gonorrhoeae strain. Emerg Infect Dis. 2018;24(4):735-40. https://doi. org/10.3201/eid2404.171873.

21. Lefebvre B, Martin I, Demczuk W, Deshaies L, Michaud S, Labbé AC, et al. Ceftriaxone-resistant Neisseria gonorrhoeae, Canada, 2017. Emerging Infect Dis. 2018;24(2):381-3. https://doi.org/10.3201/eid2402.171756.

22. Terkelsen D, Tolstrup J, Johnsen CH, Lund O, Larsen HK, Worning P, et al. Multidrug-resistant Neisseria gonorrhoeae infection with ceftriaxone resistance and intermediate resistance to azithromycin, Denmark, 2017. Euro Surveill. 2017;22(42):17-00659. https://doi.org/10.2807/1560-7917.ES.201 7.22.42.17-00659

23. Poncin T, Fouere S, Braille A, Camelena F, Agsous M, Bebear C, et al. Multidrug-resistant Neisseria gonorrhoeae failing treatment with ceftriaxone and doxycycline in France, November 2017. Euro Surveill. 2018;23(21): 1800264. https://doi.org/10.2807/1560-7917.ES.2018.23.21.1800264.

24. Golparian D, Rose L, Lynam A, Mohamed A, Bercot B, Ohnishi M, et al. Multidrug-resistant Neisseria gonorrhoeae isolate, belonging to the internationally spreading Japanese FC428 clone, with ceftriaxone resistance and intermediate resistance to azithromycin in Ireland, august 2018. Euro Surveill. 2018;23(47):1800617. https://doi.org/10.2807/1560-7917.ES.2018.23.4 7.1800617.

25. Eyre DW, Sanderson ND, Lord E, Regisford-Reimmer N, Chau K, Barker L, et al. Gonorrhoea treatment failure caused by a Neisseria gonorrhoeae strain with combined ceftriaxone and high-level azithromycin resistance, England, February 2018. Euro Surveill. 2018;23(27):1800323. https://doi.org/10.2807/1 560-7917.ES.2018.23.27.1800323.

26. Unemo M. Current and future antimicrobial treatment of gonorrhoea - the rapidly evolving Neisseria gonorrhoeae continues to challenge. BMC Infect Dis. 2015;15(1):364. https://doi.org/10.1186/s12879-015-1029-2.

27. Fifer H, Natarajan U, Jones L, Alexander S, Hughes G, Golparian D, et al. Failure of dual antimicrobial therapy in treatment of gonorrhea. N Engl J Med. 2016;374(25):2504-6. https://doi.org/10.1056/NEJMc1512757.

28. Lan PT, Golparian D, Ringlander J, Van Hung L, Van Thuong N, Unemo M. Genomic analysis and antimicrobial resistance in Neisseria gonorrhoeae isolates from Vietnam in 2011 and 2015-2016. J Antimicrobial Chemother. 2020;75(6):1432-8. https://doi.org/10.1093/jac/dkaa040.

29. Romanowski B, Robinson J, Wong T. Gonococcal infections chapter. Canadian guidelines on sexually transmitted infections. Wong T, LathamCarmanico C, editors. Ottawa: Public Health Agency of Canada; 2013. http:// www.phac-aspc.gc.ca/std-mts/sti-its/cgsti-ldcits/assets/pdf/section-5-6-eng. pdf (Accessed 19 July 2020)

30. Australasian Sexual Health Alliance (ASHA). Gonorrhoea. Australian STI management guidelines for use in primary care: ASHA; 2018. http://www.sti. guidelines.org.au/sexually-transmissible-infections/gonorrhoea\#management (Accessed 19 July 2020).

31. St Cyr S, Barbee L, Workowski KA, Bachmann LH, Pham C, Schlanger K, et al. Update to CDC's treatment guidelines for gonococcal infection, 2020. MMWR Morb Mortal Wkly Rep. 2020;69(50):1911-6. https://doi.org/10.15585/ mmwr.mm6950a6.
32. Fifer H, Saunders J, Soni S, Sadiq ST, FitzGerald M. 2018 UK national guideline for the management of infection with Neisseria gonorrhoeae. Int J STD AIDS. 2020;31(1):4-15. https://doi.org/10.1177/0956462419886775.

33. Boiko I, Golparian D, Krynytska I, Bezkorovaina H, Frankenberg A, Onuchyna $M$, et al. Antimicrobial susceptibility of Neisseria gonorrhoeae isolates and treatment of gonorrhoea patients in Ternopil and Dnipropetrovsk regions of Ukraine, 2013-2018. APMIS. 2019;127(7):503-9. https://doi.org/10.1111/a pm.12948.

34. Japanese Society for Sexually Transmitted Infections. Gonococcal infection. Sexually transmitted infections, diagnosis and treatment guidelines 2011. Jpn J Sex Transm Dis. 2011;22(Suppl. 1):529 (in Japanese).

35. Jennison AV, Whiley D, Lahra MM, Graham RM, Cole MJ, Hughes G, et al. Genetic relatedness of ceftriaxone-resistant and high-level azithromycin resistant Neisseria gonorrhoeae cases, United Kingdom and Australia, February to April 2018. Euro Surveill. 2019;24(8). https://doi.org/10.2807/1 560-7917.ES.2019.24.8.1900118.

36. Cole MJ, Spiteri G, Jacobsson S, Woodford N, Tripodo F, Amato-Gauci AJ, et al. Overall low extended-spectrum cephalosporin resistance but high azithromycin resistance in Neisseria gonorrhoeae in 24 European countries, 2015. BMC Infect Dis. 2017;17(1):617. https:/doi.org/10.1186/s12879-017-2707-z.

37. Harris SR, Cole MJ, Spiteri G, Sánchez-Busó L, Golparian D, Jacobsson S, et al. Public health surveillance of multidrug-resistant clones of Neisseria gonorrhoeae in Europe: a genomic survey. Lancet Infect Dis. 2018;18(7):75868. https://doi.org/10.1016/S1473-3099(18)30225-1.

38. Martin IM, Hoffmann S, Ison CA, ESSTI Network. European Surveillance of Sexually Transmitted Infections (ESSTI): the first combined antimicrobial susceptibility data for Neisseria gonorrhoeae in Western Europe. J Antimicrob Chemother. 2006;58:587-93. https://doi.org/10.1093/jac/dkl265.

39. Glazkova S, Golparian D, Titov L, Pankratova N, Suhabokava N, Shimanskaya I, et al. Antimicrobial susceptibility/resistance and molecular epidemiological characteristics of Neisseria gonorrhoeae in 2009 in Belarus. APMIS. 2011; 119(8):537-42. https://doi.org/10.1111/j.1600-0463.2011.02770.x.

40. Lebedzeu L, Golparian D, Titov L, Pankratava N, Glazkova S, Shimanskaya I, et al. Antimicrobial susceptibility/resistance and NG-MAST characterisation of Neisseria gonorrhoeae in Belarus, Eastern Europe, 2010-2013. BMC Infect Dis. 2015;15(1):29. https://doi.org/10.1186/s12879-015-0755-9.

41. Kubanova A, Frigo N, Kubanov A, Sidorenko S, Priputnevich T, Vachnina T, et al. National surveillance of antimicrobial susceptibility in Neisseria gonorrhoeae in 2005-2006 and recommendations of first-line antimicrobial drugs for gonorrhoea treatment in Russia. Sex Transm Infect. 2008;84(4): 285-9. https://doi.org/10.1136/sti.2007.029033.

42. Kubanova A, Frigo N, Kubanov A, Sidorenko S, Lesnaya I, Polevshikova S, et al. The Russian gonococcal antimicrobial susceptibility programme (RUGASP)-national resistance prevalence in 2007 and 2008, and trends during 2005-2008. Euro Surveill. 2010;15(14):19533. https://doi.org/10.2807/ese.1 5.14.19533-en.

43. Kubanova A, Kubanov A, Frigo N, Solomka V, Semina V, Vorobyev D, et al. Russian gonococcal antimicrobial susceptibility programme (RU-GASP) resistance in Neisseria gonorrhoeae during 2009-2012 and NG-MAST genotypes in 2011 and 2012. BMC Infect Dis. 2014;14(1):342. https://doi. org/10.1186/1471-2334-14-342.

44. Kubanov A, Vorobyev D, Chestkov A, Leinsoo A, Shaskolskiy B, Dementieva E, et al. Molecular epidemiology of drug-resistant Neisseria gonorrhoeae in Russia (current status, 2015). BMC Infect Dis. 2016;16(1):389. https://doi.org/1 0.1186/s12879-016-1688-7.

45. Clinical protocol for the diagnosis and treatment of patients with sexually transmitted infections approved by order of the Ministry of Health of the Republic of Belarus 10/29/2009, No. 1020 ("2009 Belarus national gonorrhoea guideline"). (in Russian) https://medznate.ru/docs/index-21995. html?page=2 (Accessed 30 July 2020).

46. Aniskevich AV, Shimanskaya IG. Antibacterial therapy of racing infections: problems, questions of choice of etiotropic therapy. Mil Med. 2020;2:28-33 (in Russian).

47. European Committee on Antimicrobial Susceptibility Testing. Breakpoint tables for interpretation of MICs and zone diameters Version 10.0. https:// www.eucast.org/fileadmin/src/media/PDFs/EUCAST_files/Breakpoint_tables/ v_10.0_Breakpoint_Tables.pdf (Accessed 19 July 2020).

48. Brown LB, Krysiak R, Kamanga G, Mapanje C, Kanyamula H, Banda B, et al. Neisseria gonorrhoeae antimicrobial susceptibility in Lilongwe, Malawi, 2007. Sex Transm Dis. 2010;37(3):169-72. https://doi.org/10.1097/OLQ.0b013e3181 bf575c. 
49. Unemo M, Golparian D, Sanchez-Buso L, Grad Y, Jacobsson S, Ohnishi M, et al. The novel 2016 WHO Neisseria gonorrhoeae reference strains for global quality assurance of laboratory investigations: phenotypic, genetic and reference genome characterisation. J Antimicrob Chemother. 2016;71(11): 3096-108. https://doi.org/10.1093/jac/dkw288.

50. World Health Organization. ICD-10: international statistical classification of diseases and related health problems: tenth revision, version: 2019. World Health Organization. https://icd.who.int/browse10/2019/en (Accessed 19 July 2020).

51. UNAIDS/WHO Working Group on Global HIV/AIDS and STI Surveillance. Strategies and laboratory methods for strengthening surveillance of sexually transmitted infections 2012. Geneva: World Health Organization; 2012. http://apps.who.int/iris/bitstream/10665/75729/1/9789241504478_eng.pdf (Accessed 19 July 2020).

52. Wi T, Lahra MM, Ndowa F, Bala M, Dillon JR, Ramon-Pardo P, et al. Antimicrobial resistance in Neisseria gonorrhoeae: global surveillance and a call for international collaborative action. PLoS Med. 2017;14(7):e1002344. https://doi.org/10.1371/journal.pmed.1002344.

53. Unemo M, Clarke E, Boiko I, Patel C, Patel R. Adherence to the 2012 European Gonorrhoea guideline in the WHO European region according to the 2018-19 international union against sexually transmitted infections European collaborative clinical group Gonorrhoea survey. Int J STD AIDS. 2020;31(1):69-76. https://doi.org/10.1177/0956462419879278.

54. Jacobsson S, Golparian D, Cole M, Spiteri G, Martin I, Bergheim T, et al. WGS analysis and molecular resistance mechanisms of azithromycin-resistant (MIC>2 mg/L) Neisseria gonorrhoeae isolates in Europe from 2009 to 2014. J Antimicrob Chemother. 2016;71(11):3109-16. https:/doi.org/10.1093/jac/ dkw279.

55. Boiko I, Golparian D, Jacobsson S, Krynytska I, Frankenberg A, Shevchenko T, et al. Genomic epidemiology and antimicrobial resistance determinants of Neisseria gonorrhoeae isolates from Ukraine, 2013-2018. APMIS. 2020;128(7): 465-75. https://doi.org/10.1111/apm.13060.

56. Golparian D, Bazzo ML, Golfetto L, Gaspar PC, Schörner MA, Benzaken AS, et al. Genomic epidemiology of Neisseria gonorrhoeae elucidating the gonococcal antimicrobial resistance and lineages/sublineages across Brazil, 2015-2016. J Antimicrob Chemother. 2020;75(11):3163-72. https://doi.org/1 $0.1093 / \mathrm{jac} / \mathrm{dkaa318.}$

57. Lan PT, Golparian D, Ringlander J, Van Hung L, Van Thuong N, Unemo M. Genomic analysis and antimicrobial resistance of Neisseria gonorrhoeae isolates from Vietnam in 2011 and 2015-16. J Antimicrob Chemother. 2020; 75(6):1432-8. https://doi.org/10.1093/jac/dkaa040.

58. Grad YH, Harris SR, Kirkcaldy RD, Green AG, Marks DS, Bentley SD, et al. Genomic epidemiology of gonococcal resistance to extended-spectrum cephalosporins, macrolides, and fluoroquinolones in the United States, 2000-2013. J Infect Dis. 2016;214(10):1579-87. https://doi.org/10.1093/infdis/ jiw420.

59. Demczuk W, Martin I, Peterson S, Bharat A, Domselaar GV, Graham M, et al. Genomic epidemiology and molecular resistance mechanisms of azithromycin-resistant Neisseria gonorrhoeae in Canada from 1997 to 2014. J Clin Microbiol. 2016:54(5):1304-13. https://doi.org/10.1128/JCM.03195-15.

60. Gianecini RA, Golparian D, Zittermann S, Litvik A, Gonzalez S, Oviedo C, et al. Genome-based epidemiology and antimicrobial resistance determinants in Neisseria gonorrhoeae isolates with decreased susceptibility and resistance to extended-spectrum cephalosporins in Argentina, 20112016. J Antimicrob Chemother. 2019;74(6):1551-9. https://doi.org/10.1093/ja c/dkz054.

61. Williamson DA, Chow EPF, Gorrie CL, Seemann T, Ingle DJ, Higgins N, et al. Bridging of Neisseria gonorrhoeae lineages across sexual networks in the HIV pre-exposure prophylaxis era. Nat Commun. 2019;10(1):3988. https://doi. org/10.1038/s41467-019-12053-4.

62. Peng JP, Yin YP, Chen SC, Yang J, Dai XQ, Zheng HP, et al. A whole-genome sequencing analysis of Neisseria gonorrhoeae isolates in China: an observational study. EClinicalMedicine. 2019;7:47-54. https://doi.org/10.1016/ j.eclinm.2019.01.010

\section{Publisher's Note}

Springer Nature remains neutral with regard to jurisdictional claims in published maps and institutional affiliations.

Ready to submit your research? Choose BMC and benefit from:

- fast, convenient online submission

- thorough peer review by experienced researchers in your field

- rapid publication on acceptance

- support for research data, including large and complex data types

- gold Open Access which fosters wider collaboration and increased citations

- maximum visibility for your research: over $100 \mathrm{M}$ website views per year

At BMC, research is always in progress.

Learn more biomedcentral.com/submissions 